\title{
Dual-Cationic Poly(ionic liquid)s Carrying 1,2,4-Triazolium and Imidazolium Moieties: Synthesis and Formation of a Single- Component Porous Membrane
}

\author{
Wei Cao, Liangxiao Tan, Hong Wang, and Jiayin Yuan*
}

Cite This: ACS Macro Lett. 2021, 10, 161-166

Read Online

ABSTRACT: Both imidazolium and 1,2,4-triazolium cations are important functional moieties widely incorporated as building blocks in poly(ionic liquid)s (PILs). In a classical model, a PIL usually contains either imidazolium or 1,2,4-triazolium in its repeating unit. Herein, via exploiting the slight reactivity difference of alkyl bromide with imidazole and 1,2,4-triazole at room temperature, we synthesized dual-cationic PIL homopolymers carrying both imidazolium and 1,2,4-triazolium moieties in the same repeating unit, that is, an asymmetrically dicationic unit. We investigated their fundamental properties, for example, thermal stability and solubility, as well as their unique function in forming supramolecular porous membranes via a water-initiated phase-separation and cross-linking process. With such knowledge, we identified a water-based fabricate strategy toward air-stable porous membranes from single-component PILs. This study will enrich the design tools and chemical structure library of PILs and expand their application spectrum.

$\mathrm{T}$ he types of cations in poly(ionic liquid)s (PILs) have been traditionally focused on imidazolium, pyridinium, ammonium, and phosphonium. ${ }^{1-4}$ Among them, the imidazolium cation has been playing a dominant role since the research concept of PILs emerged in the polymer community around 2000 . $^{5,6}$ The popularity of imidazolium cations ${ }^{7-16}$ in PIL chemical structure design lies in the following facts. (1) Imidazolium-based ionic liquids (ILs) are among the best studied ILs because of their rich chemical structures. When researchers think of polymerizing ILs, it is no doubt that imidazolium-based ILs come first. (2) Imidazolium is known to be associated with some unique properties, such as high thermal and chemical stability, aromaticity, rich forms of supramolecular interactions, and abundance in heteroatoms. (3) Easy access to imidazolium-based IL monomers. There is a giant library of commercial imidazole compounds that can be easily converted to their IL monomers. A classic example is 1vinylimidazole that, via a simple step of quaternization reaction with alkyl halide, can readily form a polymerizable IL.

Lately, there have been surging activities to build up PILs from triazoliums, including 1,2,3-triazolium ${ }^{17-21}$ and 1,2,4triazolium. $^{22-27}$ From a chemical structure point of view, replacement of only a single carbon atom in an imidazolium ring produces either 1,2,3-, or 1,2,4-triazolium, depending on the relative position of the added nitrogen atom in the fivemembered heterocyclic ring. ${ }^{21}$ This minor change of the chemical structure of PILs can drastically alter their global

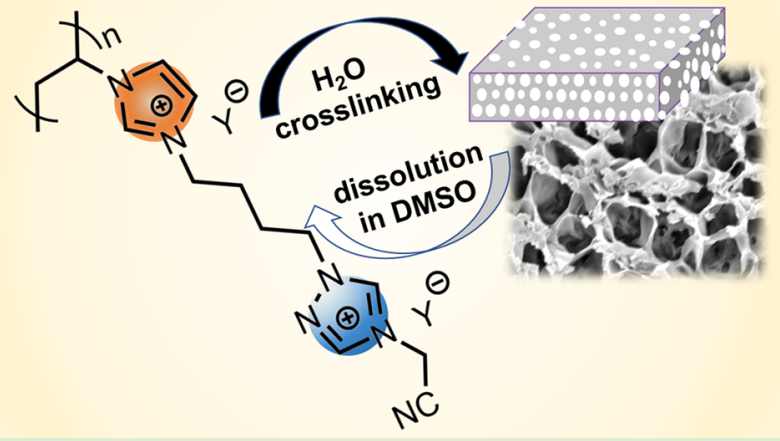

physicochemical properties. For example, poly(3-n-dodecyl-1vinylimidazolium bromide) nanoparticles prepared in water are onion-like spheres, while poly(4-n-dodecyl-1-vinyl-1,2,4-triazolium bromide) nanoparticles are wasp-like ellipsoids; ${ }^{25}$ poly(3methyl-1-vinylimidazolium TFSI) (TFSI stands for the bis(trifluoromethane sulfonyl)imide anion) in contact with water does not form a regular structure, while poly(4-methyl-1-vinyl1,2,4-triazolium TFSI) can be physically cross-linked by water molecules through $\mathrm{H}$-bonds into a porous membrane in wet conditions. ${ }^{28}$ Such distinctive behaviors of polytriazoliums initiate a rising wave to understand their intrinsic structureproperty relationships and explore their applications in sorption, catalysis, sensors, and more. ${ }^{28-30}$

The physical and chemical properties of polyimidazoliums and polytriazoliums have been investigated individually to date. It raises a question in our mind: what if these two cations are localized in a single dicationic repeating unit of PILs? As such a structure is unusual and synthetically challenging, it has so far not been reported. Note that there have been a few studies reporting PILs of dicationic repeating units, for example, 1,2,3-

Received: November 5, 2020

Accepted: January 6, 2021

Published: January 8, 2021 


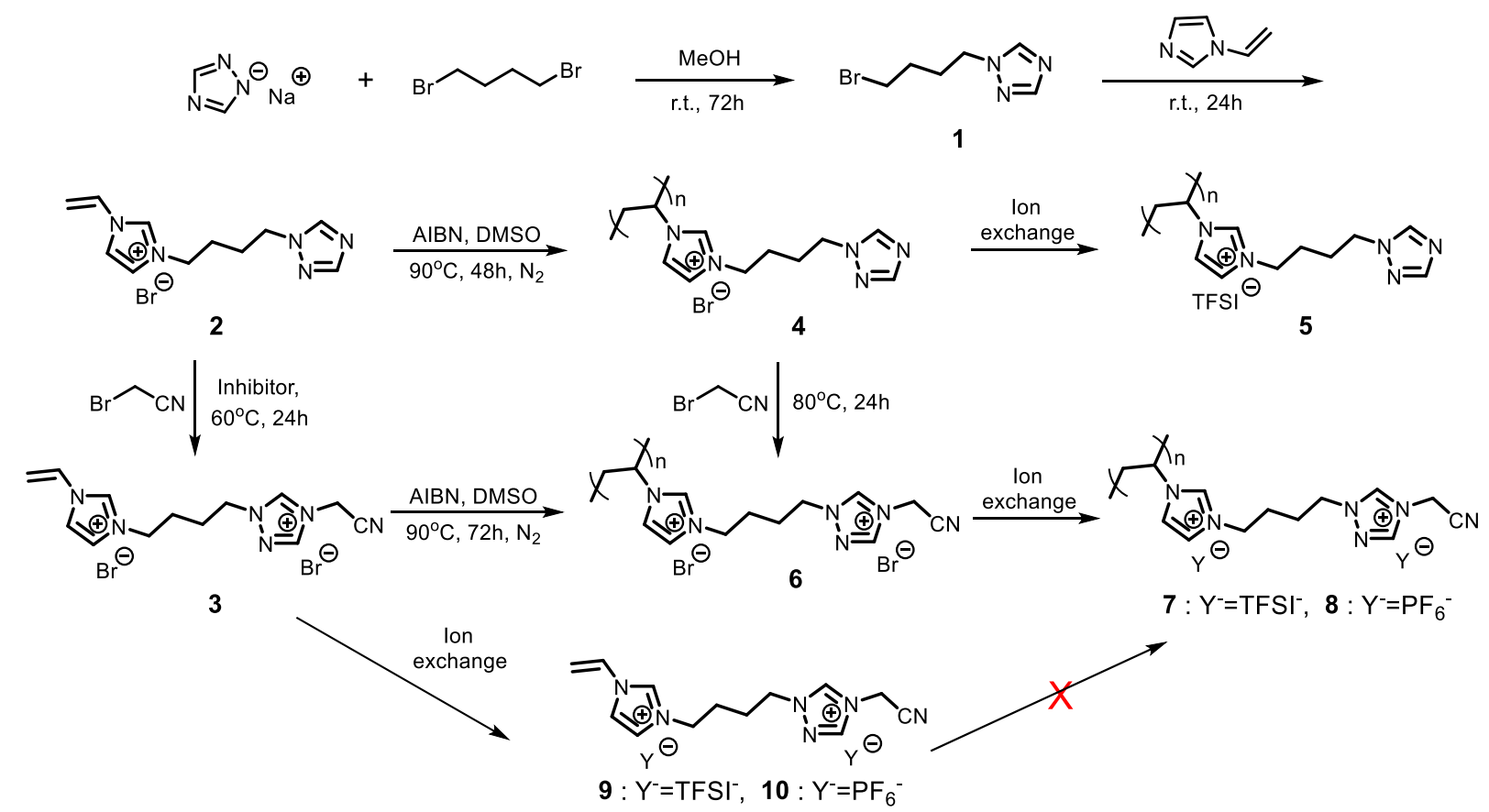

Figure 1. Schematic representation of the synthesis of 1,2,4-triazolium/imidazolium-type dicationic PILs.
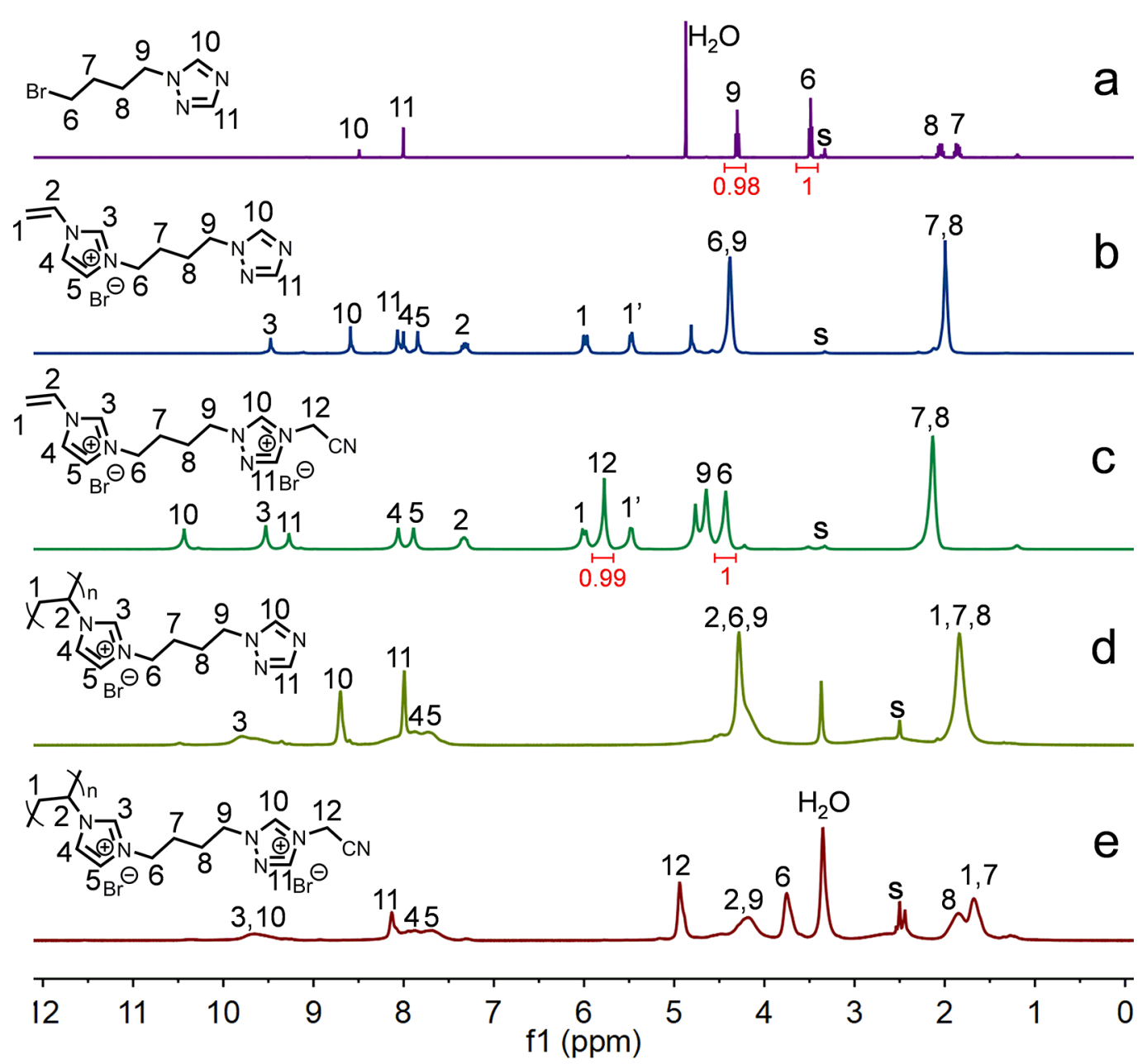

Figure 2. ${ }^{1} \mathrm{H}$ NMR spectra of (a) compound 1, (b) monomer 2, (c) monomer 3, (d) polymer 4, and (e) polymer 6. For Figure $2 \mathrm{a}-\mathrm{c}$, $\mathrm{CD}_{3} \mathrm{OD}$ was used as the solvent; for Figure $2 \mathrm{~d}, \mathrm{e}, \mathrm{DMSO}-d_{6}$ was used as the solvent. 
triazolium/1,3-thiazolium ${ }^{31,32}$ and 1,2,3-triazolium/1,2,3-triazolium $^{33}$ ones. Driven by curiosities and wishes to expand the structural toolbox of PILs, we reported herein the synthesis of 1,2,4-triazolium/imidazolium-type dicationic PILs, and their capability of forming air-stable single-component porous membranes.

The overall synthetic route is displayed in Figure 1. It starts with a reaction of sodium 1,2,4-triazolate with 1,4-dibromobutane to afford a mono- $\mathrm{Br}$ compound $\mathbf{1}$, the structure of which was confirmed by ${ }^{1} \mathrm{H}$ and ${ }^{13} \mathrm{C}$ NMR spectroscopy (spectra in Figures 2a, S1, and S2). It is a stable compound in either a solid or solution state at room temperature (r.t.), as the sample shows no difference in its NMR spectra after storage at r.t. for 2 days. The integration ratio of peak $9\left(-\mathrm{CH}_{2}\right.$ triazole) to $6\left(\mathrm{Br}-\mathrm{CH}_{2}^{-}\right)$is 0.98 (theoretical value $\left.\sim 1.00\right)$ in its ${ }^{1} \mathrm{H}$ NMR spectrum (Figure 2a), confirming the mono- $\mathrm{Br}$ compound $\mathbf{1}$ as the sole product. Bear in mind that it is crucial to keep 1,4-dibromobutane in a minimum 2-fold excess with respect to sodium 1,2,4-triazolate to suppress the formation of di-Br compound as byproduct (see synthetic details in the SI). With a moderate yield of $41 \%$, this reaction proceeded in a mild condition for easy scale-up. Next, an $\mathrm{N}$-alkylation reaction of compound $\mathbf{1}$ with 1 -vinylimidazole was performed to afford monomer 2 , a crucial step in the entire synthetic line. Here, the alkyl bromide moiety was subjected to both 1,2,4-triazole and imidazole compounds at r.t., where only the latter reacts readily with the alkyl bromide. Figure $2 \mathrm{a}$ and $\mathrm{b}$ compare the ${ }^{1} \mathrm{H}$ NMR spectra of compound 1 and monomer 2 . The chemical shift of the $\mathrm{Br}-\mathrm{CH}_{2}$ - protons (peak 6 in Figure 2a) at $3.48 \mathrm{ppm}$ vanished completely after quaternization, and a new one at 4.38 ppm (imidazolium- $\mathrm{CH}_{2^{-}}$, peak 6 in Figure $2 \mathrm{~b}$ ) emerged, indicative of a successful conversion of compound $\mathbf{1}$ to monocationic monomer 2.

Dicationic monomer 3 formed upon a second $\mathrm{N}$-alkylation reaction of monomer 2 with bromoacetonitrile at $60{ }^{\circ} \mathrm{C}$ in the presence of butylated hydroxytoluene (BHT) as an inhibitor. In its ${ }^{1} \mathrm{H}$ NMR spectrum in Figure $2 \mathrm{c}$, a single peak emerges at $5.77 \mathrm{ppm}$ (peak 12), which is assigned to the $\mathrm{CN}-\mathrm{CH}_{2}$ protons. The integration ratio of peak $12 / 6$ in Figure $2 \mathrm{c}$ is measured to be 0.99 (theoretical value $\sim 1.00$ ), proving a quantitative alkylation reaction. The specific integration and assignment of peaks in ${ }^{1} \mathrm{H}$ and ${ }^{13} \mathrm{C}$ NMR spectra of monomers $\mathbf{2}$ and $\mathbf{3}$ are displayed in Figures S3-S6, which agree well with their chemical structures.

After obtaining monomers 2 and 3, free radical polymerizations were conducted to synthesize $\mathrm{Br}^{-}$-containing polymers 4 and 6, respectively. As shown in Figure 2b,c, the vinyl proton signals $1,1^{\prime}$, and 2 at $7.32,5.99$, and 5.48 ppm, respectively, vanished after polymerization; two new signals originated from the backbone protons of the corresponding polymers appeared (peaks 1 and 2 at 4.28 and 1.84 ppm in Figure $2 \mathrm{~d}$ for polymer 4, and peaks 1 and 2 at 4.31 and $1.75 \mathrm{ppm}$ in Figure 2e for polymer 6, respectively). In addition, the broadening effect of proton signals in their polymers (Figure $2 \mathrm{~d}, \mathrm{e}$ ) in comparison to the corresponding monomers (Figure $2 \mathrm{~b}, \mathrm{c}$ ) is clear to see because of a slower molecular motion of macromolecular chains than monomers of a lower molecular weight. More details of ${ }^{1} \mathrm{H}$ and ${ }^{13} \mathrm{C}$ NMR spectra of polymers can be found in Figures S7-S10. A supportive proof of polymer formation is provided by Fourier-transform infrared (FT-IR) spectroscopy. The stretching IR band of vinyl $\mathrm{C}-\mathrm{H}$ at $3100 \mathrm{~cm}^{-1}$ in the monomer spectra (Figure S11, highlighted by dotted blue line) shrank massively in their corresponding polymers (Figure S12).

Note that the dicationic monomer 3 was observed to polymerize with more difficulty than the monocationic monomer 2, apparently due to enhanced intermonomer electrostatic repulsion and sterical hindrance. Under the same polymerization condition for $72 \mathrm{~h}$, polymerization of monomer 3 resulted in a lower yield of $26 \%$ than monomer 2 (76\%). Aiming at a higher yield, polymer 6 could be alternatively obtained via quantitative $\mathrm{N}$-alkylation of polymer 4 with bromoacetonitrile at $80{ }^{\circ} \mathrm{C}$ for $24 \mathrm{~h}$. To stress, monomer 2 is an IL with a melting point $(\mathrm{mp})$ at $60{ }^{\circ} \mathrm{C}$, so that its polymer 4 is strictly a PIL, while monomer 3 is an organic salt with a mp of $140{ }^{\circ} \mathrm{C}$ (Figure S17), defining its polymer 6 as a classic ionic polymer. Gel permeation chromatography (GPC) tests were performed to determine their macromolecular characteristics, showing a monomodal molecular weight $\left(\mathrm{M}_{\mathrm{W}}\right)$ distribution with an apparent $M_{W}$ of $133 \mathrm{kDa}$ with a polydispersity index (PDI $\sim 4.5$ ) for polymer 4 , and $24 \mathrm{kDa}$ with a PDI $\sim 2.0$ for polymer 6, respectively (Figure S15).

Next, anion metathesis reactions of polymers 4 and 6 were performed with LiTFSI and $\mathrm{KPF}_{6}$ salts to produce polymer 5 and polymers $7 / 8$, respectively (Figure 1 ). Since $\mathrm{PF}_{6}^{-}$and TFSI $^{-}$anions are $\mathrm{H}$-free and silent in ${ }^{1} \mathrm{H}$ NMR (see corresponding ${ }^{1} \mathrm{H}$ - and ${ }^{13} \mathrm{C}$ NMR spectra in Figures S22S27), the anion exchange reactions were proven by FT-IR spectra of these polymers (Figure S12). Polymers 5 and 7 with TFSI $^{-}$anions display four characteristic bands at 1343, 1133, 611 , and $600 \mathrm{~cm}^{-1}$ (dotted purple line in Figure S12) from the asymmetric/symmetric stretching and bending of the $=\mathrm{SO}_{2}$ group of the $\mathrm{TFSI}^{-}$anion. ${ }^{34}$ Polymer 8 with a $\mathrm{PF}_{6}^{-}$anion shows a broad band at $820 \mathrm{~cm}^{-1}$ (dotted brown line in Figure S12), which can be assigned to the symmetric stretching of $\mathrm{PF}_{6}{ }^{-35}$. Similarly, anion exchange was conducted to dicationic monomer 3 to produce monomers $\mathbf{9}$ and $\mathbf{1 0}$ with $\mathrm{TFSI}^{-}$and $\mathrm{PF}_{6}{ }^{-}$, respectively. Both monomers 9 and $\mathbf{1 0}$ are ILs; the former is a r.t. IL with a glass transition temperature $\left(T_{\mathrm{g}}\right)$ of $-25{ }^{\circ} \mathrm{C}$ (Figure S13), and the latter $\left(T_{\mathrm{g}} \sim 10{ }^{\circ} \mathrm{C}\right)$ becomes a viscous liquid above $80{ }^{\circ} \mathrm{C}$ (Figures $\mathrm{S} 14$ and S17). In this context, both polymers 7 and $\mathbf{8}$ belong to the PIL family. It is worth mentioning that, despite our various attempts, we failed in the synthesis of polymers 7 and $\mathbf{8}$ directly from radical polymerization of monomers 9 and 10, respectively. Presumably, the strong intermonomer electrostatic repulsion in the superposition of the large-sized anions eventually blocked chain growth in polymerization.

The thermal properties of polymers $4-8$ were investigated by thermal gravimetric analysis (TGA) and differential scanning calorimetry (DSC). We found that their thermal properties are strongly anion-dependent, typically observed for PILs. As seen in Figure S16, the thermal decomposition temperatures $\left(T_{\mathrm{d}}\right.$, defined as $10 \mathrm{wt} \%$ mass loss) for $\mathrm{TFSI}^{-}$bearing polymers 5 and 7 , were found to be 336 and $345{ }^{\circ} \mathrm{C}$, respectively, which are expectedly higher than their corresponding $\mathrm{Br}^{-}$-containing polymers $4\left(274^{\circ} \mathrm{C}\right)$ and $6\left(285^{\circ} \mathrm{C}\right)$. To our surprise, $\mathrm{PF}_{6}{ }^{-}$-containing polymer 8 presents the lowest $T_{\mathrm{d}}$ of $252{ }^{\circ} \mathrm{C}$. The weakened thermal stability of polymer 8 was presumably caused by a residue of $14.8 \mathrm{~mol} \%$ of $\mathrm{Br}$ - anions, which was proven by a $\mathrm{AgPF}_{6}$ titration test (see SI for details). The DSC traces of polymers $\mathbf{4 - 8}$ are displayed in Figure $S 18$, showing a $T_{\mathrm{g}}$ at about $80{ }^{\circ} \mathrm{C}$ for $\mathrm{Br}^{-}$-containing polymer 4 and 6 , and a lower $T_{\mathrm{g}}$ at ca. $60{ }^{\circ} \mathrm{C}$ for $\mathrm{TFSI}^{-}$- 
containing polymers 5 and 7 due to a plasticizing effect of large-sized TFSI ${ }^{-}$anion. Meanwhile, $\mathrm{PF}_{6}{ }^{-}$-containing polymer 8 exhibited no detectable $T_{\mathrm{g}}$ up to $240^{\circ} \mathrm{C}$. The solubility table of polymers 4-8 (Table S1) presents characteristic anionadaptive solubility.

Having 1,2,4-triazolium/imidazolium dicationic PILs in hand, we were interested in exploring their functions and applications. Recently we discovered that some TFSI ${ }^{-}$containing poly(1,2,4-triazolium) and occasionally also polyimidazolium could be cross-linked via $\mathrm{H}$-bonding by water molecules into porous membranes, a processing technique that allows for "green" membrane fabrication. Unfortunately, these reported porous structures in water lost pores upon warming or drying at ambient condition, that is, the pores are only stable in wet conditions unless being freeze-dried. ${ }^{28}$

Here, we tested $\mathrm{TFSI}^{-}$-containing dicationic polymer 7 for this pore-forming behavior in water, as the $\mathrm{TFSI}^{-}$anion is required to make polymer 7 hydrophobic enough to induce phase separation in contact with water. The detailed fabrication procedure is illustrated in Figure 3a. First, a

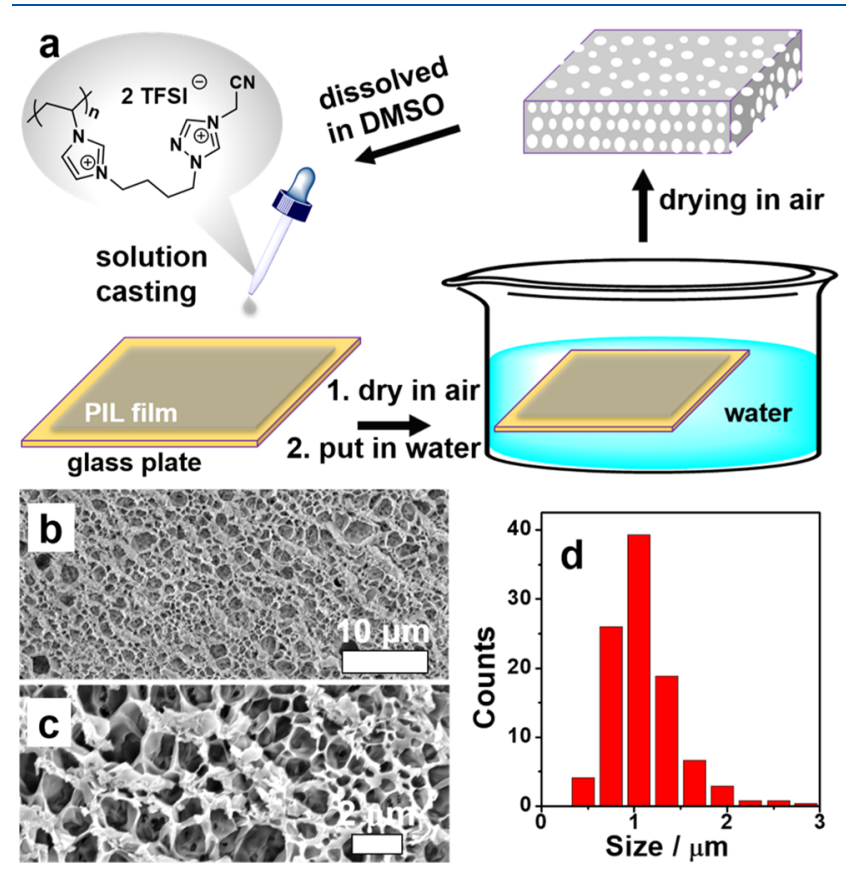

Figure 3. (a) Fabrication scheme of a porous membrane from polymer 7 in water; (b, c) SEM images of the cross-sectional view of the porous membrane made from polymer 7 after annealed in water for $12 \mathrm{~h}$; (d) its pore size distribution histogram.

DMSO solution of polymer 7 was cast onto a glass plate and dried at $80{ }^{\circ} \mathrm{C}$ for $3 \mathrm{~h}$ into a transparent yellowish thin film, which according to the scanning electron microscopy (SEM) analysis is dense and pore-free (Figure S19). This film was immersed in water for $12 \mathrm{~h}$, during which it became opaque. Finally, the sample was taken out and dried in a fume hood under an ambient environment to a constant weight. Its SEM image visualizes an interconnected porous architecture from its top to bottom (Figure $3 b, c$ ). The membranes prepared by this method are generally $5-20 \mu \mathrm{m}$ in thickness, depending on the thickness of the original films on the glass plate. The average pore size is $1.1 \pm 0.3 \mu \mathrm{m}$ with a monomodal pore size distribution (Figure 3d). It is noteworthy that 1,2,4-triazoliumfree polymer $\mathbf{5}$ failed to form pores along the same fabrication procedure (Figure S20), as the 1,2,4-triazolium cation assists the formation of strong hydrogen bonds with water molecules.

Surprisingly, the porous membrane formed in water remains porous even after being dried in air. Thermogravimetric analysis shows that the membrane has no weight loss $(<1 \mathrm{wt}$ $\%$ ) up to $200{ }^{\circ} \mathrm{C}$ (Figure S21), implying the absence of water molecules. This observation is different from our recent report that the pores formed in water and cross-linked by H-bonds were only stable in a wet condition. ${ }^{28} \mathrm{We}$ attribute the capability of porous structures to survive the dry process, to the high-content of $\mathrm{TFSI}^{-}$anions (2 per repeating unit) that sufficiently stabilize the phase-separated porous structure, even after removal of water molecules. Note that the dried membrane is soluble in DMSO upon gentle warming, allowing for full recycle and reuse of the membrane materials. This discovery provides a fabrication strategy of supramolecular porous membranes from single-component PILs.

In summary, homopolymer-type PILs containing both imidazolium and 1,2,4-triazolium cations in the repeating unit have been synthesized. As expected, the relatively high charge density in monomers makes it difficult to directly polymerize dicationic monomers with large-sized counteranions. Such PILs in contact with water produce porous membranes that are air-stable after drying in ambient conditions. The design and synthesis of asymmetrically dicationic PILs will not only enrich the chemical structure library of PILs, but also contribute to the green fabrication techniques for porous membranes.

\section{ASSOCIATED CONTENT}

\section{Supporting Information}

The Supporting Information is available free of charge at https://pubs.acs.org/doi/10.1021/acsmacrolett.0c00784.

Materials, instrumentation, experimental procedure, ${ }^{1} \mathrm{H}$ and ${ }^{13} \mathrm{C}$ NMR spectra of the monomers/polymers, FTIR spectra and DSC curves of the monomers/polymers, photos of monomer 9 and 10, TGA curves of the polymers, and the SEM images of membranes before and after annealing in water (PDF)

\section{AUTHOR INFORMATION}

\section{Corresponding Author}

Jiayin Yuan - Department of Materials and Environmental Chemistry, Stockholm University, Stockholm 10691, Sweden; ○ orcid.org/0000-0003-1016-5135; Email: jiayin.yuan@ mmk.su.se

\section{Authors}

Wei Cao - Department of Materials and Environmental Chemistry, Stockholm University, Stockholm 10691, Sweden

Liangxiao Tan - Department of Materials and Environmental Chemistry, Stockholm University, Stockholm 10691, Sweden

Hong Wang - Key Laboratory of Functional Polymer Materials, Ministry of Education), Institute of Polymer Chemistry, College of chemistry, Nankai University, Tianjin 300071, People's Republic of China; (1) orcid.org/00000003-4260-3734

Complete contact information is available at: https://pubs.acs.org/10.1021/acsmacrolett.0c00784 


\section{Author Contributions}

The manuscript was written through contributions of all authors. All authors have given approval to the final version of the manuscript.

\section{Notes}

The authors declare no competing financial interest.

\section{ACKNOWLEDGMENTS}

J.Y. is grateful for financial support from European Research Council (ERC) Starting Grant NAPOLI-639720, Swedish Research Council Grant 2018-05351, Dozentenpreis 15126 from Verband der Chemischen Industrie e.V. (VCI) in Germany, the Wallenberg Academy Fellow program (Grant KAW 2017.0166) in Sweden, and the Stockholm University Strategic Fund SU FV-2.1.1-005.

\section{REFERENCES}

(1) Lu, J.; Yan, F.; Texter, J. Advanced applications of ionic liquids in polymer science. Prog. Polym. Sci. 2009, 34, 431-448.

(2) Yuan, J.; Mecerreyes, D.; Antonietti, M. Poly(ionic liquid)s: An update. Prog. Polym. Sci. 2013, 38, 1009-1036.

(3) Shaplov, A.; Marcilla, R.; Mecerreyes, D. Recent Advances in Innovative Polymer Electrolytes based on Poly(ionic liquid)s. Electrochim. Acta 2015, 175, 18-34.

(4) Bara, J. E.; O'Harra, K. E. Recent Advances in the Design of Ionenes: Toward Convergence with High-Performance Polymers. Macromol. Chem. Phys. 2019, 220, 1900078.

(5) Ohno, H.; Ito, K. Room-temperature molten salt polymers as a matrix for fast ion conduction. Chem. Lett. 1998, 27, 751-752.

(6) Hirao, M.; Ito, K.; Ohno, H. Preparation and polymerization of new organic molten salts; $\mathrm{N}$-alkylimidazolium salt derivatives. Electrochim. Acta 2000, 45, 1291-1294.

(7) Yan, F.; Texter, J. Solvent-Reversible Poration in Ionic Liquid Copolymers. Angew. Chem., Int. Ed. 2007, 46, 2440-2443.

(8) Yuan, J.; Soll, S.; Drechsler, M.; Müller, A. H. E.; Antonietti, M. Self-Assembly of Poly(ionic liquid)s: Polymerization, Mesostructure Formation, and Directional Alignment in One Step. J. Am. Chem. Soc. 2011, 133, 17556-17559.

(9) la Cruz, D. S.; Green, M. D.; Ye, Y.; Elabd, Y. A.; Long, T. E.; Winey, K. I. Correlating backbone-to-backbone distance to ionic conductivity in amorphous polymerized ionic liquids. J. Polym. Sci., Part B: Polym. Phys. 2012, 50, 338-346.

(10) Cordella, D.; Kermagoret, A.; Debuigne, A.; Riva, R.; German, I.; Isik, M.; Jeróme, C.; Mecerreyes, D.; Taton, D.; Detrembleur, C. Direct Route to Well-Defined Poly(ionic liquid)s by Controlled Radical Polymerization in Water. ACS Macro Lett. 2014, 3, 12761280

(11) Cordella, D.; Kermagoret, A.; Debuigne, A.; Jérôme, C.; Mecerreyes, D.; Isik, M.; Taton, D.; Detrembleur, C. All Poly(ionic liquid)-Based Block Copolymers by Sequential Controlled Radical Copolymerization of Vinylimidazolium Monomers. Macromolecules 2015, 48, 5230-5243.

(12) Nykaza, J. R.; Ye, Y.; Nelson, R. L.; Jackson, A. C.; Beyer, F. L.; Davis, E. M.; Page, K.; Sharick, S.; Winey, K. I.; Elabd, Y. A. Polymerized ionic liquid diblock copolymers: impact of water/ion clustering on ion conductivity. Soft Matter 2016, 12, 1133-1144.

(13) Schreiner, C.; Bridge, A. T.; Hunley, M. T.; Long, T. E.; Green, M. D. Segmented imidazolium ionenes: Solution rheology, thermomechanical properties, and electrospinning. Polymer 2017, $114,257-265$.

(14) Erwin, A. J.; Lee, H.; Ge, S.; Zhao, S.; Korolovych, V. F.; He, H.; Matyjaszewski, K.; Sokolov, A. P.; Tsukruk, V. V. Viscoelastic properties and ion dynamics in star-shaped polymerized ionic liquids. Eur. Polym. J. 2018, 109, 326-335.

(15) Dunn, C. A.; Shi, Z.; Zhou, R.; Gin, D. L.; Noble, R. D. (Crosslinked Poly(ionic liquid)-Ionic Liquid-Zeolite) Mixed-Matrix
Membranes for $\mathrm{CO}_{2} / \mathrm{CH}_{4}$ Gas Separations Based on Curable Ionic Liquid Prepolymers. Ind. Eng. Chem. Res. 2019, 58, 4704-4708.

(16) Wang, Y.; Shao, Y.; Wang, H.; Yuan, J. Advanced Heteroatomdoped Porous Carbon Membranes Assisted by Poly(ionic liquid) Design and Engineering. Acc. Mater. Res. 2020, 1, 16-29.

(17) Jeong, Y.; Ryu, J.-S. Synthesis of 1,3-Dialkyl-1,2,3-triazolium Ionic Liquids and Their Applications to the Baylis-Hillman Reaction. J. Org. Chem. 2010, 75, 4183-4191.

(18) Sanghi, S.; Willett, E.; Versek, C.; Tuominen, M.; Coughlin, E. B. Physicochemical properties of 1,2,3-triazolium ionic liquids. RSC Adv. 2012, 2, 848-853.

(19) Mudraboyina, B. P.; Obadia, M. M.; Allaoua, I.; Sood, R.; Serghei, A.; Drockenmuller, E. 1,2,3-Triazolium-Based Poly(ionic liquid)s with Enhanced Ion Conducting Properties Obtained through a Click Chemistry Polyaddition Strategy. Chem. Mater. 2014, 26, $1720-1726$

(20) Jourdain, A.; Serghei, A.; Drockenmuller, E. Enhanced IonicConductivity of a 1,2,3-Triazolium-Based Poly(siloxane ionic liquid) Homopolymer. ACS Macro Lett. 2016, 5, 1283-1286.

(21) Obadia, M. M.; Drockenmuller, E. Poly(1,2,3-triazolium)s: a new class of functional polymer electrolytes. Chem. Commun. 2016, $52,2433-2450$.

(22) Xue, H.; Gao, H. X.; Shreeve, J. M. Energetic polymer salts from 1-vinyl-1,2,4-triazole derivatives. J. Polym. Sci., Part A: Polym. Chem. 2008, 46, 2414-2421.

(23) De La Hoz, A. T.; Miller, K. M. Covalently crosslinked 1,2,4triazolium-containing polyester networks prepared by Michael addition polymerization. Polymer 2015, 72, 1-9.

(24) Nakabayashi, K.; Umeda, A.; Sato, Y.; Mori, H. Synthesis of 1,2,4-triazolium salt-based polymers and block copolymers by RAFT polymerization: Ion conductivity and assembled structures. Polymer 2016, 96, 81-93.

(25) Zhang, W.; Kochovski, Z.; Lu, Y.; Schmidt, B.; Antonietti, M.; Yuan, J. Internal Morphology-Controllable Self-Assembly in Poly(Ionic Liquid) Nanoparticles. ACS Nano 2016, 10, 7731-7737.

(26) Lo, C.; Isawa, Y.; Nakabayashi, K.; Mori, H. Design of ionconductive core-shell nanoparticles via site-selective quaternization of triazole-triazolium salt block copolymers. Eur. Polym. J. 2018, 105, 339-347.

(27) Yahia, M.; Mei, S.; Mathew, A. P.; Yuan, J. Linear Main-Chain 1,2,4-Triazolium Poly(ionic liquid)s: Single-Step Synthesis and Stabilization of Cellulose Nanocrystals. ACS Macro Lett. 2019, 8, 1372-1377.

(28) Shao, Y.; Wang, Y.; Li, X.; Khorsand Kheirabad, A.; Zhao, Q. Yuan, J.; Wang, H. Water can Crosslink a Single Poly(ionic liquid) into Porous Supramolecular Membranes. Angew. Chem., Int. Ed. 2020, 59, 17187-17191.

(29) Zhang, S. Y.; Miao, H.; Zhang, H. M.; Zhou, J. H.; Zhuang, Q.; Zeng, Y. J.; Gao, Z.; Yuan, J.; Sun, J. -K. Accelerating Crystallization of Open Organic Materials by Poly(ionic liquid)s. Angew. Chem., Int. Ed. 2020, 59, 22109.

(30) Zhang, S.-Y.; Zhuang, Q.; Zhang, M.; Wang, H.; Gao, Z.; Sun, J.-K.; Yuan, J. Poly(ionci liquid) composites. Chem. Soc. Rev. 2020, 49, $1726-1755$

(31) Tejero, R.; Lopez, D.; Lopez-Fabal, F.; Gomez-Garces, J. L.; Fernandez-Garcia, M. Antimicrobial Polymethacrylates based on Quaternized 1,3-Thiazole and 1,2,3-Triazole Side-Chain Groups. Polym. Chem. 2015, 6, 3449-3459.

(32) Tejero, R.; Arbe, A.; Fernandez-Garcia, M.; Lopez, D. Nanostructuration by Self-Assembly in N-Alkyl Thiazolium and Triazolium Side-Chain Polymethacrylates. Macromolecules 2015, 48, $7180-7193$.

(33) Obadia, M. M.; Jourdain, A.; Serghei, A.; Ikeda, T.; Drockenmuller, E. Antimicrobial Cationic and dicationic 1,2,3triazolium-based poly(ethylene glycol ionic liquid)s. Polym. Chem. 2017, 8, 910-917.

(34) Höfft, O.; Bahr, S.; Kempter, V. Investigations with Infrared Spectroscopy on Films of the Ionic Liquid [EMIM]Tf ${ }_{2} \mathrm{~N}$. Langmuir 2008, 24, 11562-11566. 
(35) Talaty, E. R.; Raja, S.; Storhaug, V. J.; Dölle, A.; Carper, W. R. Raman and Infrared Spectra and ab Initio Calculations of $\mathrm{C}_{2-4}$ MIM Imidazolium Hexafluorophosphate Ionic Liquids. J. Phys. Chem. B 2004, 108, 13177-13184. 